\title{
Is There such a Thing as an »Offensive Picture «?
}

Christoph Baumgartner

\section{Introduction}

In our descriptions of pictures, we often ascribe particular qualities to paintings, photographs, drawings, and the like. Some of these qualities can be understood as »objective properties in the sense that anyone who is familiar with the meaning of a specific concept can identify whether or not a particular picture actually has the property denoted by the respective concept. Michelangelo's fresco The Last Judgment in the Sistine Chapel, for instance, is a colored and figurative picture, and Kazimir Malevich's Black Square is monochrome and abstract. If someone were to claim that The Last Judgment was abstract and monochrome rather than figurative and colored, we could explain what we mean by »figurative« and »colored «, and we could try to convince that person that these concepts apply to The Last Judgment. If she insisted that Michelangelo's fresco was abstract and monochrome, she wouldn't merely describe the picture differently, she would describe at least some of the qualities of Michelangelo's The Last Judgment incorrectly. This is different in the case of characteristics such as »kitschy«, which we usually do not understand as matters of fact. Rather, the qualification of a picture as kitschy is dependent on personal taste or culturally dominant aesthetic norms and ideals. Accordingly, it is possible that people disagree about whether or not a picture qualifies as kitsch without making incorrect statements in the sense outlined above.

How then should we understand the notion of an offensive picture in light of the above? The notion of an offensive picture has been important in the context of public debates and ethical and legal analyses of, for instance, the exhibition or publication of images such as Andres Serrano's Piss Cbrist, a photograph of a crucifix that is submerged in a glass of urine, Chris Ofili's The Holy 
Virgin Mary, a painting of Mary as a black woman in a blue robe made of elephant dung and pornographic cutouts (among other materials), or the Danish so-called Muhammad cartoons that were first published by the newspaper Jyllands-Posten. ${ }^{1}$ Can we reasonably argue that in specific instances offensiveness is an »objective property« of a picture? Or is the offensiveness that some people experience in view of some pictures something that exists merely in the eye or the heart of the beholder? The answers to such questions are relevant for our understanding of people's responses to particular pictures; they are also important for the ethical and legal assessment of the relevant cases. In this paper, however, my main interest is in the more fundamental question of how we should understand the notion of an offensive picture from a philosophical perspective, if it turns out in the course of analysis to be a meaningful concept at all.

I begin with a brief clarification of the notion of a picture and an exploration of the broader terminological field in which »offense is situated in philosophical discourse. Here I make use of Joel Feinberg's distinction between various modes of offense and of Martha Nussbaum's work on disgust. I will then critically discuss two theoretical approaches that I treat as candidates that could possibly provide a framework within which the notion of an offensive picture could be understood and defended: Leon Kass's argument from the wisdom of repugnance, and cognitive-evaluative theories of emotions. Having identified the limitations of these approaches, I will conclude by suggesting that Harry Frankfurt's theory of caring can be used, in combination with insights from research on the use of pictures in religious practices, to improve the explanatory power of cognitive-evaluative theories of emotions for answering the question whether and to what extent the notion of an offensive picture is a meaningful concept. 


\section{$»$ Picture « and $»$ offense $«-$ conceptual clarifications}

The concept »picture « as I use it in this paper denotes a material object that is meant to be seen by someone. ${ }^{2}$ In other words, a picture is a visual medium that is used, and usually also produced, to let people see particular things. The thing that is seen, then, is the image that »appears in a picture. $\ll^{3}$ Images of visual things are dependent on pictures, since images never appear »except in some medium or another «, but unlike a picture, the image is not a material object; »you can hang a picture, but you can't hang an image. « ${ }^{4}$ However, as W.J.T. Mitchell and Hans Belting point out, images can survive the pictures in which they first appear, and iconoclasm can destroy only a picture, not the image, since images can be memorized and re-materialized in new pictures or other media, such as stories or songs. Accordingly, an image can migrate through different media, and it can be conserved or transformed in this process. Unlike an image, a picture is constituted and defined by its materiality, and, as I use the concept here, by its artificiality and its purpose to show something. This means that, for instance, Niagra Falls is not a picture, whereas an artificial depiction of the falls, for instance in the form of a painting, a drawing, a photograph, or a digital file on a computer screen, is.

An analysis of the notion of »offensive picture « is complicated by the fact that the concept »offense « is relatively broad and includes various levels and dimensions. On the one hand, offense denotes an action, namely a transgression of a rule or norm; in the legal context, for example, offense refers to violating laws and committing crimes. ${ }^{6}$ In the context of an analysis of offensive pictures, however, »offense« more often refers to the effect of a deed or an event: the offense 
that someone takes at something. Joel Feinberg, who investigated this notion of offense from a philosophical perspective, understands such offense in a general sense as a variety of disliked mental states and emotions such as disgust, shame, hurt, repugnance or anxiety. ${ }^{7}$ Within this broad conceptual field of emotional distress, Feinberg distinguishes three different modes of offense. First, there are »affronts to the senses; « here, the disliked emotions that constitute offense derive as it were directly and entirely from the sound, smell, or sight at which one takes offense - »and not at all from any symbolic representation, or recognized object. $\ll^{8}$ In other words, affronts to the senses are independent of specific beliefs about the source of the offense; at least this is how someone who takes offense in the sense of affronts to the senses experiences the offense. This is different in the case of the second mode of offense: offenses to sensibilities. These are, according to Feinberg, mediated by recognition or belief in the sense that the disliked emotions of which offense consists follow from a specific cognition of the source of offense. This cognition can be implicit and habituated, but unlike in the case of sensuous affronts, a person's emotional response to a particular object or event changes if the person's understanding of the respective object or event changes in a relevant way. Take as an example the emotional and visceral responses of many people to the sight of a public toilet smeared with human excrement and vomit: they feel disgust and revulsion. Often, we experience such emotional responses as immediate and purely visceral, but the same sight - that is the same forms and colors - provokes different emotions if we recognize the object as a clean and hygienic artifact, for example an art work, consisting of plastic or chocolate and butter cream. This demonstrates that it is the subject's conception of the object - what she »thinks « she sees in the partic- 
ular situation - that is or is not offensive. Accordingly, Feinberg points out, disgust is not merely an affront to the senses, but an offense to sensibility that he defines as »the susceptibility to offense from witnessing objects or events which, because of the observer's recognition of them as objects of a certain kind, are painful for him to behold. « ${ }^{9}$ In many cases, susceptibility to offense, and hence offenses to sensibilities, depend on cutoms and conventions that are embodied in the identity of the person who takes offense at something. Because of this deep rootedness of sensibilities, offenses to sensibilities are usually experienced as spontaneous, pre-rational or even quasi-natural. Various analyses of disgust as a specific form of offense show this clearly. Joel Feinberg, for instance, argues that, to induce disgust, it is sufficient that we recognize a situation as somebody eating something that violates our gastronomic sensibility. ${ }^{\text {Io }}$ Similarly, Winfried Menninghaus characterizes disgust as a »spontaneous and especially energetic act of saying >no« This act of saying "no « and of forcibly distancing oneself from the thing one finds disgusting is experienced as something that »overcomes us, unannounced and uncontrollable, taking sudden possession of us « and as a »compulsion to say no, an inability not to say no. $\ll^{12}$ The fact that disgust and other forms of offenses to sensibilities are, on the one hand, perceived as a »quasi-automatic (instinctives) form of nay-saying, ${ }^{\text {"3 }}$ while being dependent on beliefs and the recognition of specific (features of) objects, on the other hand, constitutes what one could call a »paradox of offenses to sensibilities." How can we understand this paradox?

Martha Nussbaum's theory of disgust provides a useful tool for answering such questions. Nussbaum conceptualizes disgust in line with Feinberg, 
Menninghaus, and other authors as an aversive emotion that, on the one hand, is especially visceral (it involves, e.g., strong bodily reactions to the point of retching and vomiting), but that, on the other hand, has a complex cognitive content; a core that can be reconstructed in terms of beliefs and value judgments. ${ }^{14}$ More specifically, Nussbaum explains disgust as emotional warnings against »contaminants, " objects that are »understood « (albeit implicitly) by the person who is disgusted as rendering unacceptable a substance that can enter our bodies. ${ }^{15}$ Although there is a variety of possible objects of disgust, one can identify a group of »core objects of disgust, « all of which are in one way or the other related to animal (including human) matter, especially animal waste products, which we usually see as debasing. ${ }^{16}$ Such objects are »ubiquitously objects of disgust, « Nussbaum argues, and »societies seem not to have latitude to make these primary objects non-disgusting. $\aleph^{17}$ An average person feels disgust or similar forms of offenses to sensibilities when he or she sees such objects, especially in view of the prospect of touching, smelling, swallowing, or being penetrated by them or by things that have been in contact with such core objects of disgust, since in such situations the aspect of contamination and, resulting from this, debasement or dehumanization are especially palpable. This aspect of debasement and dehumanization is decisive, here, since the core idea of disgust is, according to Nussbaum,

the belief that if we take in the animalness of animal secretions we will ourselves be reduced to the status of animals. Similarly, if we absorb or are mingled with the decaying, we will ourselves be mortal and decaying. Disgust thus wards off both animality in general and the mortality that is so prominent in our loathing of our animality. ${ }^{18}$ 
Against this background, we can better understand the aforementioned "paradox of offenses to sensibilities. Certain forms of offense, such as disgust in view of feces, vomit, etc., include a quasi-cognitive core: the recognition of the object of disgust as contaminant. The »knowledge « whether or not an object is contaminating (in the sense that is relevant for disgust) relates to and is part of the corporality and vulnerability that is common to all human beings, independent of particular cultural and social circumstances. Accordingly, disgust and other forms of offenses to sensibilities are experienced as »objective« and direct bodily sensations and as things that befall us and are completely out of our control; the object of disgust actually is disgusting, independent of somebody's specific character traits and personal identity. This is different in the case of the third mode of offense that Joel Feinberg identifies: offenses to higher-level sensibilities and profound offense. ${ }^{19}$ Such offenses to higher-level sensibilities are intrinsically related to and determined by a person's morality or religion and the beliefs, values, and ideals that are part of this. One's higherlevel sensibilities are offended if and only if she understands an act or event as a violation or denigration of her morality or religion. Take the example of burning, trampling on, or cutting into pieces a national flag. Such acts can offend the higher-level sensibilities of an individual whose morality includes a form of patriotism that requires people to treat the national flag with respect; people who don't hold such principles won't be offended by seeing, for instance, a burning flag. Similarly, people can take offense at the presence of a pig at certain places (or at pork on their dishes) if they consider pigs impure, for instance for religious reasons. In other words, the production of offenses to higher-level sensibilities involves principles, values, and norms that cannot 
be traced back to a general human condition, and accordingly there cannot be any »ubiquitous objects of offenses to higher-level sensibilities.« This dependency on principles, values, and norms that are learned and influenced by culture and tradition does not mean, however, that offenses to higher-level sensibilities are experienced by the person who takes offense as being somehow »subjective« or »relative « - Offense is no less real for its dependence upon values and tastes peculiar to a particular culture or system of belief. ${ }^{20}$ Rather, the opposite is true: If the relevant moral or religious principles, values, and norms are constitutive for the self-understanding of a person, she can be profoundly offended by violations of such principles, values, and so forth. Such profound offense is experienced as »shattering « and »serious, « and - importantly - »in the case of profound offense [...] something offends us and not merely our senses or lower order sensibilities. $\ll^{21}$

Summing up these conceptual considerations, we can distinguish a picture as a material object that is meant to be seen by somebody from an image as the immaterial »thing « that appears in a picture and that can migrate through different media. Moreover, there are different modes of offense: affronts to the senses and offenses to sensibilities that can include offenses to higher-level sensibilities and profound offense, which are dependent on moral or religious beliefs, norms, values, and so forth that are deeply rooted in the identity of a person. The distinctions between various modes of offense are analytical in the sense that they can help us to better understand and explain the reasons and roots of offense in different cases. As will become clear in the following section, however, the different modes of offense actually merge in the concrete experiences of people who take offense at something. 
So what do these distinctions yield for an analysis of the question whether there is such a thing as an offensive picture? Can they help us to understand and conceptualize the notion of an offensive picture, and if so, how?

\section{Leon Kass's theory of »wisdom of repugnance « and a strong notion of offensive pictures}

If people take offense at pictures, all three modes of offense could possibly be involved. In the following, however, I will focus on the exploration of possible understandings of pictures that are offensive in the sense of offenses to sensibilities, since only these modes of offense are relevant for an analysis of pictures such as those mentioned at the beginning of this paper.

One could argue that especially vivid pictures of »core objects of disgust as Nussbaum describes them are offensive in the sense that the sensibilities of virtually everyone are offended by the sight of such pictures, since the images that are evoked by such pictures almost necessarily cause people to feel, for example, disgust. To such pictures, a »strong notion of an offensive picture « could be applied; this concept would include pictures that evoke, as it were inevitably, images that are offensive to virtually all spectators. But even if we granted this, the use of such a strong notion of offensive pictures for our understanding of pictures such as Piss Christ, The Holy Virgin Mary, or the Danish Muhammad cartoons would be very limited. For the revulsion that is part of the responses of those who take offense at such pictures includes a moral component that is expressed by people's protest against the production, display, and sometimes 
the sheer existence of such pictures. So the mode of the offense that people take at such pictures is obviously different from that of disgust as Martha Nussbaum and others describe it. Accordingly, the notion of offensive pictures could possibly be better understood within the framework of an approach that integrates a theory of specific disliked emotions and modes of offense with an analysis of instances of moral revolt. Leon Kass's argument from the wisdom of repugnance provides such a framework. ${ }^{22}$

Kass developed this argument in the context of the bioethical debate about the reproductive cloning of human beings; he starts with the observation (or assertion) that people usually respond to the prospect of cloning humans with specific, strong emotions.

»Offensive.«»Grotesque.« »Revolting.« »Repugnant.«»Repulsive.«These are the words most commonly heard regarding the prospect of human cloning. Such reactions come both from the man or woman in the street and from the intellectuals, from believers and atheists, from humanists and scientists. ${ }^{23}$

These emotional responses indicate, according to Kass, that people reject reproductive human cloning because of a number of phenomena that, he asserts, accompany it and that people intuitively and universally recognize a morally problematic, such as the »mass production of human beings, with large clones of look-alikes, compromised in their individuality; the idea of father-son or mother-daughter twins $[\ldots] . \ll^{24}$ Although, as Kass admits, the fact that people feel revulsion or similar emotions in view of an object or event does not show 
that the respective object or event actually is morally problematic, he argues that »in crucial cases [...] repugnance is the emotional expression of deep wisdom, beyond reason's power fully to articulate it. «25 The cloning of human beings is, according to Kass, such a crucial case, and actually »repugnance may be the only voice left that speaks up to defend the central core of our humanity. Shallow are the souls that have forgotten how to shudder. $\ll^{26}$

This argument from the wisdom of repugnance is based on the assumptions that there are objects and practices that have a status as »ubiquitous objects of repugnance and that all people have a natural capacity to identify and be alerted to these objects or practices. People who are not offended by the sight or the prospect of such objects or practices experience them not only differently, but also wrongly, and their capacity to adequately respond to such objects is deficient, or, to put it in Leon Kass's words, their souls are »shallow« and they have »forgotten how to shudder.«

Anthony Fisher and Hayden Ramsay have used the argument from the wisdom of repugnance in their ethical analysis of Andres Serrano's Piss Cbrist; "popular repugnance at sacrilege and blasphemy, « they claim, is also an example of a »crucial case in which the wisdom of repugnance informs us about certain features of particular practices or objects. ${ }^{27}$ Unfortunately, Fisher and Ramsay don't elaborate on this any further, but their claim that Piss Cbrist is a picture to which the appropriate response is repugnance seems to be based on a strong notion of an offensive picture as I delineated it above. Moreover, they have to assume in their argument that Piss Christ is an instance of such a picture. The latter assumption could possibly be supported by pointing out that urine was used 
for the production of Piss Christ and that it is part of the title of the artwork. However, people who took offense at Piss Christ did not complain about the use of specific matter as such, but about the fact that a crucifix was brought into contact with urine. Immersing a crucifix in urine and taking a photo of it, as Serrano did, however, is more an instance of a transgression of a religious norm and hence of »matter out of place (Mary Douglas) from the perspective of people whose religion prescribes that (particular) religious objects should (not) be treated in specific manner than it is an instance of a ubiquitous object of offense to sensibilities. This dependency of the offense that people take at pictures like Piss Christ on a particular religion that is not rooted in the universal human condition, but is highly contested in contexts of religious diversity, makes it impossible to speak about, for instance, Piss Christ as an offensive picture in the strong sense. Hence, the argument from the wisdom of repugnance fails to provide a framework within which we could adequately understand and defend the notion of offensive pictures.

At first sight, the problem of the dependency of offense to (higher-level) sensibilities on beliefs, norms, and so forth that are not part of the universal human condition seems to be fatal also for cognitive-evaluative theories of emotions, which are a second candidate for a theoretical framework for a philosophical understanding of a notion of an offensive picture. ${ }^{28}$ Nevertheless, I would argue such theories provide insights that enable us to understand why and to what extent we can reasonably use the concept of offensive pictures in analyses of controversies about pictures like Piss Cbrist, The Holy Virgin Mary, or the Danish Muhammad cartoons. 


\section{Revising cognitive-evaluative theories of emotions in light of Harry Frankfurt's theory of caring}

Cognitive-evaluative theories conceptualize emotions such as anger, love, grief, or fear as forms of evaluative judgments that ascribe high value to things and persons. In these judgments, people appraise the elements they value highly as salient to their well-being. ${ }^{29}$ Fear, for instance, embodies specific beliefs about an object, namely that the object is important to the person who feels fear, that it is at risk, and that the person cannot entirely control the impending bad event. As soon as the person learns that the situation actually is not dangerous, her emotion will change, and she will feel, for instance, relief..$^{\circ}$ Accordingly, cognitive-evaluative theories of emotion understand the person who feels an emotion as an active participant in and contributor to the process of evoking an emotion: although she may experience an emotion as something that overwhelms her and that she cannot control, she actually produces the necessary conditions of an emotion, for instance by valuing highly things she cannot fully control. This is an important difference from the assumptions underlying Leon Kass's argument from the wisdom of repugnance; Kass assumes that virtually all people feel repugnance and other modes of offense toward practices like the cloning of human beings, as it were, »naturally« or quasi-automatically (like a technical measuring instrument). Advocates of cognitive-evaluative theories, by contrast, impute to persons (indirect) responsibility for their emotions. Generally, someone has indirect responsibility for something if the person is able to control and cultivate (some of) the circumstances that give rise to a particular deed, attitude, event, and so forth. In the case of emotions, people are, to a certain extent, 
responsible for whether they maintain particular values (that were acquired earlier in the process of socialization) on which emotions depend, and hence »we can cultivate and habituate emotions by attaching more or less value to certain things. $\ll^{3 \mathrm{I}}$ For offenses to higher-level sensibilities in Feinberg's sense, this means that a person is indirectly responsible for taking offense at, for example, Chris Ofili's The Holy Virgin Mary, insofar as she is responsible for the susceptibility to offense from witnessing (or knowing about) transgressions of specific religious norms concerning the use of matter like elephant dung and pornographic cutouts in relation to the Virgin Mary. She will be susceptible to taking offense at this art work and similar pictures only if Mary is religiously or morally important for her (or if she highly values Mary for some other reasons) and if she judges the piece as defiling the Virgin Mary and Her holiness. ${ }^{32}$

At first sight, a strong notion of an offensive picture seems to be implausible within the framework of such cognitive-evaluative theories of emotions. Rather than supporting a strong notion of an offensive picture, such an understanding of emotions accords with W.J.T. Mitchell's claim that it is not the material picture that offends, but the image that is actively (albeit not necessarily knowingly and deliberately) evoked in the spectator. »A picture, « Mitchell writes,

is less like a statement or speech act [...] than like a speaker capable of an infinite number of utterances. An image is not a text to be read but a ventriloquist's dummy into which we project our own voice. When we are offended by what an image >says, $<$ we are like the ventriloquist insulted by his own dummy. ${ }^{33}$ 
Mitchell's considerations seem to suggest that spectators who do or do not take offense at pictures like The Holy Virgin Mary, Piss Christ, or the Danish Muhammad cartoons always act as ventriloquists and that they simply make the dummy (i.e., the image that appears to them in the picture) say very different things because they value highly different things. In light of this, the production of a ubiquitously offensive picture (in the sense of offenses to higher-level sensibilities) would be impossible, since somebody's attempt to produce such a picture will always fail, if spectators don't contribute to the process as described above.

Analyses of recent public controversies about art works, cartoons, movies, and so forth at which many religious people took offense demonstrate that there is a strong predominance of the cognitive-evaluative approach on the part of secular and liberal critics of protests against such images. In the debate about the Danish Muhammad cartoons, for instance, believers who based their complaints about the cartoons on the claim that the cartoons offended their religious sensibilities were construed as being oversensitive, and protesting Muslims were told that they shouldn't take religion too seriously. Obviously, the predominant expectation was that citizens of democratic and pluralistic societies »ought to keep a critical distance to [their] commitments, particularly if these are religious commitments. «4

An important component of this argument is the claim that it is wrong to ascribe too much value to things that other people dislike or object to, if one isn't willing to put up with, for example, harsh criticism and ridicule of the things that one values. Such an argument, however, rests upon a misunderstanding of what valuing means in the context of emotions related to religion and of the status of the judgments that are related to it.

Valuing something $(\mathrm{x})$ can be generally understood to involve various ele- 
ments: ${ }^{35}$ a belief that $\mathrm{X}$ is good or worthy, a susceptibility to experience contextdependent emotions concerning $\mathrm{x}$, a disposition to experience these emotions as being merited or appropriate, and a disposition to treat considerations related to $\mathrm{X}$ as reasons for action in relevant contexts. A devout Catholic who values the Virgin Mary, for example, believes that Mary is »good « (deserves to be valued); the valuing person is susceptible to emotions such as joy or grief in relation to the Virgin Mary; she considers her emotions appropriate; and, finally, her valuing Mary will give her reasons for action, for instance to say the Hail Mary. It is also possible that her valuing the Virgin Mary extends to depictions of Mary - it will possibly provide reasons to contemplate icons of the Virgin Mary, and she will be vulnerable to emotions such as anger, grief, or hurt if she notices that somebody destroys such icons or uses matter such as feces and pornographic cutouts for pictures of the Virgin Mary. In light of this, it seems possible only to speak of offensive images, but not of offensive pictures, since exactly the same picture (the material object) will be offensive for some but not for others, depending on whether or not different people value the picture highly. In the context of offenses that are related to religion and religious objects such as pictures, however, the problem with this view of valuing is that it construes the relationship between the valuing person and the object that is valued as a relation between two entities that remain separate from each other. In so doing, it neglects an important aspect of profound offense: profound offense is related to things, beliefs, or practices that are not only valued as external objects, but that are part and parcel of the identity of the valuing person. ${ }^{6}$ From a philosophical perspective, this can be reconstructed in terms of caring about something as Harry Frankfurt has conceptualized it. ${ }^{37}$ People, he argues, have 
certain »ideals, «things they care about. When a person cares about something, she regards it as important in the sense that her desires and wishes are structured by what she cares about, and certain wishes are deemed more important than others. Such caring is not primarily a matter of believing that something is or should be important, but it is »constituted by a complex set of cognitive, affective, and volitional dispositions and states. $\ll^{3^{8}}$ Moreover, what one actually and effectively cares about is often not under one's immediate control, and is also not only an individual affair, since people are brought up in particular cultural and social contexts and »grow into « traditions and cultures within which they share important objects of caring. They are members of various communities, and all of this is relevant to what they care about and to what extent they are able and willing to critically reflect upon and either reaffirm or possibly try to reshape what they care about, and hence their own identities.

Similar to valuing, caring about something implies that one considers something good, and both valuing and caring about something involve a specific susceptibility to emotions that are related to the object of valuing and caring. The characteristic feature of caring that is decisive in the context of my analysis of the notion of offensive pictures, however, is that caring »incorporates « the thing a person cares about into her identity. Of course, the object of one's caring is not dissolved in this process; rather,

a person who cares about something is, as it were, invested in it. $\mathrm{He}$ identifies himself with what he cares about in the sense that he makes himself vulnerable to losses and susceptible to benefits depending upon whether what he cares about is diminished or enhanced. ${ }^{39}$ 
In other words, caring about something is distinct from valuing something because, in the case of caring, the person and what she cares about are inextricably entangled. Somebody's object of caring is deeply incorporated in, and a defining part of, the identity of the person, and the person cannot be adequately understood without reference to what she cares about. For my question concerning the concept of an offensive picture, a further component of Frankfurt's theory of caring is especially important. In his discussion of questions related to freedom of will and autonomy, Frankfurt argues that a person can care about certain things so much and so wholeheartedly that it is impossible for her to act in a way that is inconsistent with what she cares about. In that case, according to Frankfurt, a person is subject to »volitional necessities « that make it »unthinkable« for the person to perform a certain action, since otherwise she would betray the object of her caring and hence herself. ${ }^{4}$ Frankfurt illustrates the effect of volitional necessities with the famous declaration by (or rather attributed to) Martin Luther, who refused the demand to retract his writings at the Diet of Worms in I52I by stating, »Here I stand, I can do no other. ${ }^{4 \mathrm{I}}$ Such examples show that volitional necessities are rightly construed as limitations of a person's freedom (Luther cannot retract his writings). At the same time, however, volitional necessities are rightly experienced as expressions of the will and the autonomy of the respective person herself. 


\section{Conclusion:}

\section{How can we understand the notion of an offensive picture?}

To what extent is Harry Frankfurt's theory more applicable to the notion of an offensive picture than Leon Kass's considerations about the wisdom of repugnance and cognitive-evaluative theories of emotions that are based on an understanding of valuing such as the one sketched above?

In light of Frankfurt's theory, a pious Catholic can be understood as one who wholeheartedly cares about a religious tradition that, along with particular practices, includes certain images (not pictures) of Jesus, saints, and the Virgin Mary, among others. These images are shared by many Catholic people; not all of them find all of the images equally important, but for some, images of, for instance, the Virgin Mary occupy a central place in their personal religious subjectivity. For them, Mary is a constitutive part of their lives in the sense that they develop, maintain, and express who they are in relation to images of Mary, for instance as loving mother, source of solace, or ideal of moral and religious purity. Whatever else may be constitutive of what they wholeheartedly care about and of what they are invested in, from Frankfurt's perspective, images of the Virgin Mary are indispensable to who they are. These images, however, do not »come to them « in an immediate way, but are evoked and actualized in various media, such as songs, prayers, and pictures. Such »sensational forms, « as Birgit Meyer calls them, »invoke and perpetuate shared experiences, emotions, and affects that are anchored in a taken-for-granted sense of self and community, $\ll^{42}$ and they do so, I suggest, through the images that appear in them to people for whom the respective sensational forms »matter in the sense of 
Harry Frankfurt's theory of caring. Without such sensational forms, the images that are essential for one's identity cannot be made »real.« Accordingly, the role of pictures in the lives of many religious people cannot be adequately described in terms of objects that are valued highly, but remain external and separate from them. Rather, the relation between a person and certain pictures can be one of constructive entanglement in the sense that it is in pictures (among other things) that people »find, « incorporate, and emulate the images in which they are invested. If that is the case, people cannot (in the sense of a volitional necessity) respond to an image they recognize as depicting something they wholeheartedly care about, on the one hand, but that, on the other hand, evokes a degradation of what they are invested in, as an »external object « of which they calmly disapprove. Rather, they are bound to take profound offense at the image that appears (to them), as it were necessarily, in the picture in question. This means that a strong notion of an offensive picture does not apply to pictures like Ofili's The Holy Virgin Mary, Serrano's Piss Christ, or the Danish Muhammad cartoons; such pictures can be profoundly offensive, but only for particular people, namely those whose object of caring includes the sacred figures that are addressed by these pictures. With the possible exception of some pictures of »ubiquitous objects of disgust « (see above), the offensiveness of a picture exists always »merely« in the mode of potentiality and is not an »intrinsic « feature of the picture by itself. However, in certain cases and for particular people this potentiality will be necessarily realized. Here, the person in question »can do no other « than to let the ventriloquist's dummy and the material picture utter a specific message - a specific image - at which the person must take offense. In such cases, I suggest, the distinction between an image to which one takes 
offense and the picture in which this image necessarily appears for the respective person is merely analytical, and because of this, and limited to such cases, the notion of an offensive picture is a meaningful concept.

These considerations are especially significant in the context of liberal and pluralistic societies. Such societies are characterized by the presence of a diversity of religious and non-religious traditions within which individuals acquire and grow into different »objects of caring « in the process of socialization. Moreover, people are free, and by educational, commercial, and other means actively stimulated »to make their own choices« and to express themselves in public. This, however, almost inevitably results in others' taking offense at someone's (verbal, material, pictorial, etc.) statements - just because people not only disagree about what is of value in their lives, including matters of religion; they also disagree about, and are imbued with, rivaling (»proper«) practices of engaging with what they do or do not care about. In light of this, we cannot be surprised by the fact that offensive pictures in the sense outlined above »exist« in liberal and pluralistic societies.

1 See, for example, Elisabeth Burns Coleman: The Offenses of Blasphemy. Messages in and through Art, in Journal of Value Inquiry 45 (2011), pp. 67-84; Anthony Fisher / Hayden Ramsay: Of Art and Blasphemy, in Ethical Theory and Moral Practice, 3 (2000), p. 137-I67; S. Brent Plate: Blasphemy. Art that Offends, London 2006; Saba Mahmood: Religious Reason and Secular Affect. An Incommensurable Divide?, in Talal Asad / Wendy Brown / Judith Butler / Saba Mahmood (eds.): Is Critique Secular? Blasphemy, Injury, and Free Speech, Berkeley, Los Angeles, London 2009 pp. 64-100.

2 For the following, see Hans Belting: An Anthropology of Images. Picture, Medium, Body, trans. by Thomas Dunlap, Princeton and Oxford 20II; and W. J. T. Mitchell: Four Fundamental Concepts of Image Science, in James Elkins (ed.): Visual Literacy, New York 2008, pp. I4-30. 
3 Mitchell: Four Fundamental Concepts of Image Science (see note 2), p. 16 .

4 Ibid., p. I6.

5 Belting: Anthropology of Images (see note 2), p. 5.

6 See Lorenz Langer: Religious Offence and Human Rights. The Implications of Defamation of Religions, Cambridge 2014 , p. 8.

7 Joel Feinberg: Offense to Others. The Moral Limits of the Criminal Law, New York and Oxford 1985. Feinberg elaborates on offense extensively in this book, and he addresses important normative questions that I don't address, because in the context of this paper I'm not interested in possible moral or political questions related to offensive pictures.

8 Ibid., p. I4.

9 Ibid., p. I6.

${ }^{10}$ Ibid., p. 16.

11 Wilfried Menninghaus: Disgust. The Theory and History of a Strong Sensation, trans. by Howard Eiland and Joel Golb, New York 2003, p. 2.

12 Ibid., p.2; (emphasis in original).

13 Ibid., p. 2.

14 See Martha Nussbaum: Hiding from Humanity. Disgust, Shame, and the Law, Princeton and Oxford 2004, pp. 87-98. Nussbaum builds her theory on insights from evolutionary theories and psychological research.

15 Ibid., p. 87.
${ }^{16}$ Ibid., p. 89.

17 Ibid., p. 91. This is part of Nussbaum's criticism of Mary Douglas's influential theory of purity and danger, according to which disgust and impurity are always socially contextual notions. What makes an object »disgusting « or »impure, « according to Douglas, is its »being out of place; « the same object may be pure and not disgusting in a different (social and/or spatial) context (see Mary Douglas: Purity and Danger. An analysis of concepts of pollution and taboo, London 1966). Nussbaum considers Douglas' approach too contextual when it comes to the analysis of our emotional responses to core objects of disgust. I don't argue that there actually are such ubiquitous objects of disgust as Nussbaum postulates them. Rather, my argument in this section is that a strict notion of an offensive picture makes sense only on the basis of certain assumptions.

${ }^{18}$ Nussbaum: Hiding from Humanity (see note I4), p. 89

19 See Feinberg: Offense to Others (see note 7), Pp. 16-18 and pp. 50-96.

${ }^{20}$ Peter Jones: Blasphemy, Offensiveness, and the Law, in British Journal of Political Science, Io (1980), Pp. 129-I48, here p. 137 .

${ }^{21}$ Feinberg: Offense to Others (see note 7), pp. 50-96, here p. 59.

${ }^{22}$ Kass, Leon: The Wisdom of Repugnance, in The New Republic, 2 June 1997, pp. 17-26.

${ }^{23}$ Ibid., p. 19

${ }^{24}$ Ibid., pp. 19-20.

25 Ibid., p. 20. 
${ }^{26}$ Ibid., p. 20. Kass's argument has been criticized massively in bioethics, but I don't go into this here, because his specific critique of cloning human beings is not relevant for my analysis of the notion of offensive pictures.

${ }^{27}$ Fisher/Ramsay: Art that Offends (see note I), P. I43.

${ }^{28}$ For the following, see Martha Nussbaum: Upheavals of Thought. The Intelligence of Emotions, New York 2001 and Aaron Ben-Ze'ev: The Subtlety of Emotions, Cambridge/ Mass. 2000.

${ }^{29}$ Nussbaum: Upheavals of Thought (see note 28), p. 19.

30 Ibid., pp. 28-29.

31 Ben-Ze'ev: Subtlety of Emotions (see note 28), p. 246.

32 One could, for instance, also appreciate the symbolic value that elephant dung has in African culture, where it is a sign of fertility. See W. J. T. Mitchell: What Do Pictures Want? The lives and loves of images, Chicago and London 2005, p. 135 .

33 Ibid., p. I40.

34 Christian F. Rostbøll: Autonomy, Respect and Arrogance in the Danish Cartoon Controversy, in Political Theory, 37/5 (2009), pp. 623-648, here p. 626.

35 For the following, see Samuel Scheffler: Equality and Tradition. Questions of Value in Moral and Political Theory, Oxford 2010 , here pp. 15-40.

${ }^{36}$ See Jojada Verrips in this volume.

${ }^{37}$ For the following, see Harry G. Frankfurt: The Importance of What We Care About: Philosophical Essays, New York 1988 and Harry G. Frankfurt: Necessity, Volition, and Love, New
York 1999.

${ }^{38}$ Frankfurt: Importance of What We Care About (see note 37), p. 85 .

${ }^{39}$ Ibid., p. 83 .

${ }^{40}$ See ibid., pp. $85-88$ and Frankfurt: Necessity, Volition, and Love (see note 37 ), Pp. IIO-II 4 .

41 Frankfurt: Importance of What We Care About (see note 37), p. 86 .

${ }^{42}$ Birgit Meyer: Religious Sensations: Why Media, Aesthetics and Power Matter in the Study of Contemporary Religion, Amsterdam 2006, p. 20. See also David Morgan: Visual Piety. A History and Theory of Popular Religious Images, Berkeley, Los Angeles, and London 1998 and Id.: The Look of the Sacred, in Orsi, Robert (ed.): The Cambridge Companion to Religious Studies, New York 20I2, pp. 296-318. 